\title{
Dark Stress to Improve Lipid Quantity and Quality in Acid-Tolerant Microalgae Exposed to Simulated (6\% C02) Flue Gas
}

\author{
Sabrina Marie Desjardins \\ Laurentian University \\ Corey Alfred Laamanen \\ Laurentian University \\ Sari Muinonen \\ Sudbury INO (a Glencore Company) \\ Nathan Basiliko \\ Laurentian University \\ John Ashley Scott ( $\nabla$ jascott@laurentian.ca ) \\ Laurentian University
}

\section{Research Article}

Keywords: Algae, flue gas, CO2, acid tolerant, dark stress, lipid production

Posted Date: May 5th, 2021

DOI: https://doi.org/10.21203/rs.3.rs-452143/v1

License: (9) This work is licensed under a Creative Commons Attribution 4.0 International License. Read Full License 


\section{Abstract}

The use of $\mathrm{CO}_{2}$ rich industrial flue gases to support cultivation of microalgae to produce lipids for biofuel and other applications is an increasingly researched option. However, this approach presents a challenge, as whilst flue gasses typically contain $6-10 \% \mathrm{CO}_{2}$, excessive medium acidification can be caused by the presence of $\mathrm{NO}_{x}$ and $\mathrm{SO}_{2}$. The use of acidophilic or acid-tolerant species is a possible solution, but little is known about these microalgae. In this study we investigated the growth of a bioprospected acid-tolerant mixed photosynthetic green microalgae culture ( $91 \%$ dominated by a single Coccomyxa sp. taxon) at pH 2.5 and fed with a simulated flue gas containing $6 \% \mathrm{CO}_{2}$ and $94 \% \mathrm{~N}_{2}$. At the end of the exponential growth phase, lipid accumulation and profiles, and the elemental composition of biomass were analysed over one week during which biomass was exposed to either continued light-dark cycle conditions or continual dark conditions. After three days of dark stress, the biomass consisted of approximately $28 \%$ of lipids, which was $42 \%$ higher than at the end of the exponential phase and $55 \%$ higher than the maximum lipid content achieved under light/dark conditions. Oleic acid (C18:1), pentadecanoic acid (C15:0), and palmitic acid (C16:0) were the dominant fatty acids at the end of the exponential phase, and light-dark and dark-treated biomass, respectively. Dark stress conditions favoured polyunsaturated fatty acid production and showed an increase in nitrogen content. This suggests that the use of dark stress to stimulate production of desirable lipids is a no-cost alternative to other commonly used stressors.

\section{Introduction}

Photosynthetic green microalgae are a diverse group of microorganisms often used to produce lipids for transesterification into biofuels [1] or human health products [2]. While microalgae biomass has the advantage of large yields per unit area [3] and the ability to grow on non-arable land, their high production costs can put them at a disadvantage when compared to other renewable and non-renewable resources, such as terrestrial plants or petrochemical oils. Various solutions to reducing the costs of cultivating microalgae at large scale include utilizing a biorefinery approach $[4,5]$, developing low-cost photobioreactors [6], and using industrial wastes, such as wastewater [7] and flue gas [8,9] as sources of nutrients and $\mathrm{CO}_{2}$. In particular, the use of industrial flue gases as sources of $\mathrm{CO}_{2}$ has been shown to be effective, including that from coal-fired boilers from a beef processing plant [10], soda boilers at a pulp and paper mill [11], and from a combined heat and power plant [12].

The presence of $\mathrm{NO}_{\mathrm{x}}$ and $\mathrm{SO}_{2}$ in flue gases can, however, cause high acidification of the growth media, and therefore to avoid costs associated with a neutralizing agent, use of acidophilic or acid-tolerant microalgae species could be crucial to advance. In recent years, there has been increasing research towards understanding the biology and ecology of acidophilic and acid-tolerant species, with species diversity at low pH being higher than previously assumed [13]. While acidic conditions are not widely used in current (non-flue-gas-using) commercial large-scale microalgae cultivation, a controlled acidic medium could reduce contamination by non-target species, which is a common problem with less selective environments that favour a more diverse suite of neutrophilic taxa [14]. 
Acid stress experienced by acidophilic and acid tolerant microalgae typically leads to the accumulation of certain lipid and carbohydrate metabolites relative to growth under circumneutral pH conditions $[15,16]$. Accumulation of highly-desirable bioactive compounds have consistently been shown to increase under nutrient starvation [17], increased irradiance [18], and increased salinity [19]. However, each of these stress-inducing environmental variables necessitate high cost at large-scale [20].

To induce the accumulation of desired biocompounds, a two-stage cultivation process is often used. Microalgae are grown to late exponential or early stationary phases under suitable growing conditions and then are put under environmental stress for a short duration. This encourages the cells to increase targeted secondary metabolites before harvesting. Whether adding a variable or taking one away, each stressor such as a modifying $\mathrm{pH}$, represents an additional process cost, including an impact on subsequent downstream processing [21]. For example, flocculation harvesting methods are impacted by the $\mathrm{pH}$ of the liquid media [22,23], which could lead to an increased use of $\mathrm{pH}$ modifying chemicals to achieve adequate harvest. Another common stress approach, use of salts, could negatively impact the ability to reduce costs through recycling media [24].

An approach to inducing the accumulation of target metabolites through a no-cost environmental stressor that also does not negatively affect downstream processes could be dark stress. There have been studies that have explored light stress via changing wavelengths [25], or by changing light intensities [26]. Increasing light penetration into a gas-lift bioreactor by modifying light exposure patterns (without increasing energy) increased lipid content by $16 \%$ [27], but total lipid content was found to double when microalgae were placed in constant dark [28]. Similarly, under combined dark and salinity stress, the marine microalgae Dunaliella tertiolecta was found to increase lipid content from $28 \%$ to $39 \%$ during 36 hours of dark [29]. Dark-induced senescence of the vascular plant Arabidopsis thaliana demonstrated an accumulation of triacylglycerides (TAGs) and lipoproteins via autophagy [30]. The process of autophagy (a mechanism induced by stress) in eukaryotic microalgae has been linked to increases in TAGs [31] and the degradation of ribosomal proteins [32] through nutrient starvation, but has yet to be linked to dark-induced stress.

In this study, we look at how applying dark stress influenced lipids of a mixed bioprospected microalgae culture enriched from a water body with a pH of 2.5. The culture was dominated (91\%) by a photosynthetic, acid-tolerant green Coccomyxa sp. microalga. Growth curves in the laboratory $(\mathrm{pH} 2.5,12$ hour photoperiod, and a bubbled in synthetic flue-gas containing $6 \% \mathrm{CO}_{2}$ ) were obtained during the exponential growth phase. Post exponential phase, lipid accumulation and profiles were then studied over seven days in cells under either a light/dark cycle or dark only regime.

\section{Material And Methods}

\subsection{Microalgae cultivation}


A microalgae consortium was bioprospected from a water body $(\mathrm{pH} 2.8)$ on an active mine site and identified to be predominantly (91\%) a single acid-tolerant Coccomyxa sp. taxon while grown at pH 2.5 based on high throughput SSU rRNA gene amplicon sequencing on the Illumina MiSeq platform using the $18 \mathrm{~S}$ primer set and methods described in Bradley et al. [33]. The remaining $9 \%$ was made up of other green microalgae, protozoa and fungi. The microalgae were inoculated in $2 \mathrm{~L}$ flasks (triplicated) containing 1.2 L of acidified (pH 2.5) Bold's basal media (BBM; [34]) with a starting density of approximately $100 \mathrm{mg} \mathrm{L}^{-1}$ dry weight biomass. The $\mathrm{pH}$ of the flasks was lowered from neutral $\mathrm{pH}$ using 1 $M$ sulfuric acid and measured daily using a calibrated Oakton ${ }^{\mathrm{TM}}$ pHTestr $^{\mathrm{TM}} 30$ (Fisher Scientific; CAT\#13200263). The flasks were placed on a gyratory shaker (Model G2, New Brunswick Scientific Co.) at $125 \mathrm{rpm}$ and maintained under red and blue LEDs (approximately $22 \mathrm{mmol} \mathrm{s}^{-1} \mathrm{~m}^{-2}$ ) with a 12-hour light/dark cycle. A simulated flue gas mixture of $6 \% \mathrm{CO}_{2}$ and $94 \% \mathrm{~N}_{2}$ was continuously bubbled through the flasks for eight hours, starting at the beginning of the 12-hour light photoperiod. This mixture, along with the $\mathrm{pH}$ modification was used to simulate acidic flue gas produced by a nickel smelter.

Daily biomass productivity was measured based on the daily increase of dry weight biomass throughout the growth period and expressed as $\mathrm{mg}_{\mathrm{dw}} \mathrm{L}^{-1}$ day ${ }^{-1}$. Average biomass productivity $\left(\mathrm{mg}_{\mathrm{dw}} \mathrm{L}^{-1}\right.$ day $\left.{ }^{-1}\right)$ was measured based on the increase of dry weight biomass from the beginning of the growth period to the end of exponential phase, and specific growth rate (day ${ }^{-1}$ ) calculated using Eq. (1):

$$
\mu=\frac{\ln ^{X_{2}} / X_{1}}{t_{2}-t_{1}}
$$

where $\mathrm{X}_{1}$ and $\mathrm{X}_{2}$ are the biomass densities $\left(\mathrm{mg}_{\mathrm{dw}} \mathrm{L}^{-1}\right)$ at the beginning and end of the exponential phase, respectively, $t_{1}$ and $t_{2}$ are the time in days at which exponential phase begins and ends, respectively.

Individual samples for lipid analysis (duplicated) and elemental analysis (duplicated) were removed from the flasks once the highest density was achieved (end of exponential phase), to be used as controls. The $\mathrm{CO}_{2}$ biofixation rate was calculated for the control sample using Eq. (2):

$$
\mathrm{CO}_{2} \text { biofixation rate }\left(m g_{d w} L^{-1} d a y^{-1}\right)=P C_{\text {carbon }}\left({ }^{M_{C O_{2}}} / M_{C}\right)
$$

where $\mathrm{P}$ is the average biomass productivity, $\mathrm{C}_{\text {carbon }}$ the carbon content (fractional), which was determined by elemental analysis (described in section 2.4), $\mathrm{M}_{\mathrm{CO} 2}$ the molecular weight of $\mathrm{CO}_{2}$, and $\mathrm{M}_{\mathrm{C}}$ the molecular weight of carbon.

\subsection{Microalgae under light-dark and dark conditions}

After exponential phase had been reached under the same growing conditions as previously mentioned (1.2 L of BBM, 12-hour light/dark cycle, $\mathrm{pH} 2.5,6 \% \mathrm{CO}_{2}$ ), the biomass experienced either light-dark or dark treatments. During light-dark treatment, the flasks remained on the gyratory shaker and the biomass after 
the exponential phase was kept under 12-hour light/dark cycle with $6 \% \mathrm{CO}_{2}$ for 7 days. Individual samples for lipid analysis (duplicated) and elemental analysis (duplicated) were removed on days 1, 2, 3, 4 , and 7. These samples represent ordinary conditions for cells during stationary and/or decline phase, and were used as comparison against the dark-treated cells. All samples were stored at $-80^{\circ} \mathrm{C}$ until the biochemical and elemental analyses were conducted.

During dark treatment, biomass obtained after the exponential phase was placed on a gyratory shaker at $125 \mathrm{rpm}$ under constant darkness for 7 days. Unlike the flasks exposed to the normal 12-hour light/dark cycle, these flasks did not receive any $\mathrm{CO}_{2}$ since photosynthesis does not occur in the dark for photosynthetic green microalgae. After the flasks were placed in the dark, individual samples for lipid analysis (duplicated) and elemental analysis (duplicated) were removed from the flasks on days 1-4, and 7 and stored as noted above.

\subsection{Lipid and elemental analysis}

For lipid analysis, frozen, wet samples were sent to Lipid Analytical Laboratories Inc. at the University of Guelph, Ontario, Canada. Lipids were extracted based on the Bligh and Dyer method [35] using tridecanoin and methyl tricosanoate (NuChek Prep, Elysian, MN, USA). The total lipid extract was quantified via transmethylation [36] to produce fatty acid methyl esters (FAMEs). Analysis of FAMEs was completed using an Agilent 7890B gas-liquid chromatograph (GC-FID) with a $60 \mathrm{~m}$ DB-23 capillary column (internal diameter of $0.32 \mathrm{~mm}$ ). Determination of the fatty acids was carried out by a $90-110 \%$ match of the peak area of the known internal standards from Sigma-Aldrich (Oakville, ON, Canada) and Nu Chek Prep.

For elemental analysis, samples were lyophilized and ground down using a mortar and pestle before being sent to the Perdue Central Analytical Facility at Laurentian University, Ontario, Canada, for analysis. Vanadium pentoxide was added to samples weighing $3-3.5 \mathrm{mg}$ to help facilitate sulfur combustion, and a Thermo Scientific ${ }^{\mathrm{TM}}$ FlashSmart ${ }^{\mathrm{TM}}$ elemental analyzer with a $2 \mathrm{~m}$ PTFE column was used to determine the relative abundance of $\mathrm{C}, \mathrm{H}, \mathrm{N}$, and $\mathrm{S}$ in the biomass. Calibration curves were created using BBOT (2,5-Bis(5-tert-butyl-benzoxazol-2yl)thiophene), and cysteine was used as a certified reference material to evaluate recovery.

Data presented are the averages \pm standard errors within their respective technical replicates. Statistical analysis of the data was conducted in R [37], and all graphical representations of the data were created using the R package ggplot2 [38]. The statistical significance threshold was placed at 0.05.

\section{Results}

\subsection{Microalgae growth}

The Coccomyxa sp. consortium showed atypical exponential growth (Fig. 1), where the lag phase included two reductions in density and where the exponential phase included varying slopes until it 
reached the highest biomass density $\left(550 \pm 36.1 \mathrm{mg} \mathrm{L}^{-1}\right)$, which was observed on day 19 . The largest increase in biomass was observed between day 17 and 18 , with a daily productivity of $130 \mathrm{mg} \mathrm{L}^{-1}$ day $^{-1}$. The average biomass productivity was $25.71 \mathrm{mg} \mathrm{L}^{-1}$ day $^{-1}$ and the average $\mathrm{CO}_{2}$ biofixation rate was 44.64 $\mathrm{mg} \mathrm{L}^{-1}$ day $^{-1}$. The exponential phase was determined to be between days 9 and 19, with a specific growth rate of $0.136 \pm 0.004$ day $^{-1}$.

\subsection{Lipid accumulation after exponential phase}

After the exponential phase, the highest total lipid content accumulated by light-dark treated cells occurred after 7 days of exposure $(17.81 \pm 1.04 \%)$ whereas continual dark-treated cells accumulated more total lipids after only 3 days of exposure (27.67 $\pm 9.92 \%)$ (Fig. 2). The main fatty acids found in all treatments are outlined in Table 1.

Table 1. Select fatty acid profiles of the biomass with post-exponential treatment (light-dark or dark) over 7 days.

\begin{tabular}{|c|c|c|c|c|c|c|c|c|}
\hline & \multicolumn{3}{|c|}{ Saturated (\%) } & \multicolumn{2}{|c|}{ Monounsaturated (\%) } & \multicolumn{3}{|c|}{ Polyunsaturated (\%) } \\
\hline & C15:0 & C16:0 & C18:0 & C16:1 & C18:1 & C18:2n6 & C18:3n3 & C18:3n6 \\
\hline \multicolumn{9}{|c|}{ Light-dark } \\
\hline Day 1 & 29.53 & 2.16 & 18.79 & 2.62 & 20.96 & 0.00 & 0.31 & 19.87 \\
\hline Day 2 & 27.48 & 1.55 & 18.92 & 2.90 & 21.78 & 0.00 & 0.35 & 22.13 \\
\hline Day 3 & 28.84 & 2.27 & 16.48 & 2.70 & 19.88 & 0.00 & 0.55 & 21.89 \\
\hline Day 4 & 35.54 & 3.93 & 16.04 & 5.04 & 16.55 & 0.31 & 0.86 & 8.59 \\
\hline Day 7 & 30.69 & 1.15 & 37.55 & 6.44 & 8.72 & 0.03 & 0.18 & 8.31 \\
\hline \multicolumn{9}{|l|}{ Dark } \\
\hline Day 1 & 13.17 & 14.10 & 8.19 & 1.55 & 19.53 & 11.03 & 13.28 & 13.48 \\
\hline Day 2 & 0.99 & 26.53 & 1.15 & 2.10 & 15.94 & 23.08 & 24.67 & 0.00 \\
\hline Day 3 & 1.05 & 31.64 & 1.03 & 2.34 & 18.91 & 20.04 & 18.46 & 0.01 \\
\hline Day 4 & 1.07 & 36.77 & 1.26 & 2.56 & 21.28 & 15.68 & 14.07 & 0.04 \\
\hline Day 7 & 1.10 & 42.90 & 1.31 & 2.77 & 23.90 & 14.10 & 7.22 & 0.10 \\
\hline
\end{tabular}

Dark treatment resulted in a larger ratio of omega-3 and omega-6 polyunsaturated fatty acids (PUFAs; $19.47 \%$ and $21.04 \%$, respectively) compared to 7 -days of light-dark treatment, which had a lower ratio $(1.94 \%$ and $9.53 \%$, respectively). While there were no significant differences between the treatments and the types of fatty acids (two-way ANOVA, $p=0.98$ ), as can be seem from Fig. 3 there were significant 
differences between saturated fatty acids (SFAs) and the monounsaturated (MUFAs) and polyunsaturated fatty acids within the samples (two-way ANOVA, $p<<0.05$ ).

\subsection{Elemental analysis after exponential phase}

Light-dark treated cells achieved their highest lipid content 7 days after the exponential growth phase, whereas dark-treated cells achieved it at 3 days after the exponential growth phase. The C:N ratio was highest $\left(11.9 \mathrm{~mol} \mathrm{~mol}^{-1}\right)$ for biomass at the end of exponential growth phase and on day 7 of light-dark stress (Table 2). Whereas, it remained generally unchanged during dark stress $\left(6.2-6.5 \mathrm{~mol} \mathrm{~mol}^{-1}\right)$. The highest sulfur content during dark stress was on day 7 at $0.67 \%$, while highest sulfur content during lightdark stress was $0.34 \%$ on day 4 . However, the elemental analysis of the biomass showed no significant differences between the stress treatments (Kruskal-Wallis rank sum, $p>0.05$ ).

Table 2. Elemental composition of the algal biomass at the end of exponential phase (control) and on the day of the highest lipid content obtained for each post-exponential treatment

\begin{tabular}{|llll|}
\hline Treatment & Highest lipid content (\%) & Carbon:nitrogen $\left(\mathrm{mol} \mathrm{mol}^{-1}\right)$ & Sulphur (\%) \\
\hline Control & $19.48 \pm 1.1$ & 11.9 & 0.11 \\
\hline Light-dark & $17.81 \pm 1.04$ & 11.9 & 0.11 \\
\hline Dark & $27.67 \pm 9.92$ & 6.4 & 0.28 \\
\hline
\end{tabular}

\section{Discussion}

Under standard growing conditions, the maximum daily productivity of $130 \mathrm{mg} \mathrm{L}^{-1}$ day $^{-1}$ of the acidtolerant bioprospected Coccomyxa sp. dominated consortium is similar to those for bioprospected acidophilic Coccomyxa onubensis [39, 40]. However, higher productivities presented by Vaquero et al. [41] and Casal et al. [42] for $C$. onubensis (410 $\mathrm{mg} \mathrm{L}^{-1}$ day $\left.^{-1}\right)$ and Coccomyxa acidophila (130-250 $\mathrm{mg} \mathrm{L}^{-1}$ day $^{-}$ $\left.{ }^{1}\right)$, suggest that further improvements can be made to enhance biomass productivity at low $\mathrm{pH}$. Increases in biomass productivity could be obtained by utilizing different growing media [43]. The BBM utilized in this experiment had an original pH of 6.6 whereas modified acid media (MAM), with an original $\mathrm{pH}$ of 4 [44], has been successfully used as a source of nutrients for acidophilic microalgae such as Chlamydomonas acidophila [45]. Furthermore, while the extent of bacterial and protozoan populations was not explored in this consortium, differing bacterial strains and protozoan species negatively affecting growth could be also likely $[46,47]$.

The average $\mathrm{CO}_{2}$ biofixation rate during the cultivation period (44.64 $\mathrm{mg} \mathrm{L}^{-1}$ day-1) was approximately half of the reported biofixation rate of the acidophilic species Chlamydomonas acidophila [48]. It is, however, worth noting that their reported specific growth rate was considerably larger $\left(0.92\right.$ day $\left.^{-1}\right)$ than our results $\left(0.136\right.$ day $\left.^{-1}\right)$. According to [49], the neutrophilic Chlorella fusca, with a growth rate of 
approximately 0.14 day $^{-1}$, also had an increased biofixation rate of $171.7 \mathrm{mg} \mathrm{L}^{-1}$ day $^{-1}$, suggesting the Coccomyxa sp. consortia would not be an ideal candidate in systems with high $\mathrm{CO}_{2}$ levels.

When cells undergo three days of dark stress after experiencing exponential phase growth, total lipid content in the cells increases. Interestingly, the most abundant fatty acids are different for each treatment. Lipid from biomass sampled at the end of the exponential phase favoured oleic acid (C18:1), whereas dark-light-treated cells favoured pentadecanoic acid (C15:0), and dark treated cells, palmitic acid (C16:0). Typically, biomass with high saturated fatty acid (SFA) and monounsaturated fatty acid (MUFA) contents are favoured for biodiesel production, as these fatty acids are easily transesterified [50]. However, $\mathrm{C} 15: 0$ has been found to have positive outcomes on human health by having anti-inflammatory, antifibrotic and red blood cell-stabilizing properties [51].

Overall, dark-treated cells had a higher variance of PUFAs (50\% on day 2) compared to the light-dark treated cells ( $25 \%$ on day 3 ) and the control (38\%), whereas the light-dark treated cells favoured SFA production ( $73 \%$ on day 7 ) and would be more suitable for biodiesel production. A possible explanation for the increase in PUFAs in dark-treated cells is that the absence of photosynthesis has been found to correlate with fatty acid composition, in particular a significant increase in PUFAs as photosynthesis rates decline [52]. Furthermore, nitrogen depleted environments can increase PUFA content within Coccomyxa microalgae [53]. However, since an increase in PUFAs is not as apparent in the light-treated cells, it can be assumed that the lack of photosynthesis attributed more to the increase in PUFAs than a lack of available nitrogen. Therefore, the higher PUFA content in dark-treated cells suggest they could be an ideal dietary supplement as these fatty acids are known for their heath beneficial properties [54, 55]. In particular, darktreated cells had a high abundance of omega- 6 fatty acids (15-26\%) including linoleic acid (C18:2n6), which has the potential to reduce the risk of cardiovascular disease and type-2 diabetes [56,57].

Elemental analysis showed the $\mathrm{C}: \mathrm{N}$ ratio for all treatments to be slightly higher than the mean $\mathrm{C}: \mathrm{N}$ of extremophilic polar microalgae $\left(5.8 \mathrm{~mol} \mathrm{~mol}^{-1}\right)$ whereas the mean C: $\mathrm{N}$ of dark stress $\left(6.4 \mathrm{~mol} \mathrm{~mol}^{-1}\right)$ and light-dark stress $\left(6.8 \mathrm{~mol} \mathrm{~mol}^{-1}\right)$ biomass was lower than the mean $\mathrm{C}: \mathrm{N}$ of temperate, non-extremophilic microalgae $\left(7.5 \mathrm{~mol} \mathrm{~mol}^{-1}\right)$ [58]. While the changes of $\mathrm{C}: \mathrm{N}$ ratios between treatments were found to be statistically insignificant, the decreased $\mathrm{C}: \mathrm{N}$ ratio of the dark-stressed microalgae could be an indication of an increase in amino acid synthesis [59], which would have a positive outcome on total protein content in the biomass and, therefore, support the use of this algae as a food nutrient enhancer. Increased nitrogen could also make lipid extracted biomass (LEB) a possible land ameliorant $[60,61]$. The microalgae or LEB could be used as either a liquid fertilizer [62] or dry fertilizer in the form of biochar [63], to increase crop yield and quality [64].

The highest sulfur content in the Coccomyxa sp. consortia was found to be $0.67 \%$ on day 7 of darktreatment. The sulfur content in the biomass can be present in bio-oil when the lipids are extracted, which is not beneficial for biofuel as it can lead to storage instability [65]. Therefore, use of a catalyst, such as a mesoporous silica nanoparticle described in Huang et al. [66], as a means to reduce sulfur content may be required [67]. Furthermore, the presence of sulphur could lead to $\mathrm{SO}_{2}$ emissions if the biomass was 
used for energy recovery. For example, pyrolysis using a fluidized bed reactor could be employed as a method to recover energy and nutrients from lipid-extracted biomass, and can recover more than $90 \%$ of the energy content in the biomass [68]. However, microalgae residue with a sulfur content of $0.44 \%$ was found to produce $\mathrm{SO}_{2}$ emissions when combusted using a fluidized bed reactor between $200-800^{\circ} \mathrm{C}$, but sharply decreased above $800^{\circ} \mathrm{C}[69]$.

\section{Conclusion}

The acid-tolerant microalgae consortia were found to grow on par with other Coccomyxa strains at low $\mathrm{pH}(\mathrm{pH} 2.5)$, with a specific growth rate of $0.136 \pm 0.004$ day $^{-1}$ and a maximum density of $550 \pm 36.1 \mathrm{mg}$ $\mathrm{L}^{-1}$. The dominant fatty acids were found to be oleic acid (end of the exponential phase), and post exponential phase, pentadecanoic acid (light-dark treated biomass), and palmitic acid (dark-treated biomass). From the results, the mixed microalgae culture accumulated the maximum level of lipids, which was after three to four days of dark treatment after the exponential growth phase. Dark stress predominantly favoured the production of polyunsaturated fatty acids (PUFAs) and resulted in a lower C:N ratio. This makes imposing dark conditions a potential stressor for photosynthetic microalgae designated for dietary supplements. By using dark stress conditions to increase total lipids and the production of PUFAs, addition of additional chemicals or energy (e.g., temperature change, increased salinity, or increased illumination) is avoided. Therefore, dark stress incurs no extra costs and has no impacts on downstream processes, allowing for easier recycling of media after microalgae harvesting. Future work includes optimizing cell densities and increasing growth rates to compete with microalgae species growing in more neutral environments.

\section{Declarations}

\section{Funding:}

This work was supported by a Mitacs Accelerate grant (IT14311)

\section{Conflict of interests/competing interests:}

The authors have no conflict of interests to declare that are relevant to the content of this article.

\section{Availability of data and material:}

Not applicable

Code availability:

Not applicable

\section{Author contributions:}


All authors contributed to the study conception and methodology. Investigation, data collection, visualization, and original draft preparation were performed by Sabrina M Desjardins. Resources were supplied by Sari Muinonen and John A Scott. Formal analysis was done by Sabrina M Desjardinds and Corey A Laamanen. Review and editing was completed by Sabrina M Desjardins, Corey A Laamanen, Nathan Basiliko, and John A Scott. Supervision was provided by Nathan Basiliko and John A Scott.

Funding acquisition was done by Sari Muinonen and John A Scott. All authors read and approved of the final manuscript

\section{References}

1. Gozmen Sanli B, Özcanli M, Serin H (2020) Assessment of thermodynamic performance of an IC engine using microalgae biodiesel at various ambient temperatures. Fuel. https://doi.org/10.1016/j.fuel.2020.118108

2. Lupette J, Benning C (2020) Human health benefits of very-long-chain polyunsaturated fatty acids from microalgae. Biochimie 178:15-25. https://doi.org/10.1016/j.biochi.2020.04.022

3. Saranya D, Shanthakumar S (2020) Effect of culture conditions on biomass yield of acclimatized microalgae in ozone pre-treated tannery effluent: A simultaneous exploration of bioremediation and lipid accumulation potential. J Environ Manag. https://doi.org/10.1016/j.jenvman.2020.111129

4. Bhattacharya M, Goswami S (2020) Microalgae - A green multi-product biorefinery for future industrial prospects. Biocatal Agric Biotechnol. https://doi.org/10.1016/j.bcab.2020.101580

5. Desjardins SM, Laamanen CA, Basiliko N, Scott JA (2020) Utilization of lipid-extracted biomass (LEB) to improve the economic feasibility of biodiesel production from green microalgae. Environ Rev 28:325-338. https://doi.org/10.1139/er-2020-0004

6. Erbland P, Caron S, Peterson M, Alyokhin A (2020) Design and performance of a low-cost, automated, large-scale photobioreactor for microalgae production. Aquac Eng. https://doi.org/10.1016/j.aquaeng.2020.102103

7. Kotoula D, Iliopoulou A, Irakleous-Palaiologou E, et al (2020) Municipal wastewater treatment by combining in series microalgae Chlorella sorokiniana and macrophyte Lemna minor: Preliminary results. J Cleaner Prod. https://doi.org/10.1016/j.jclepro.2020.122704

8. Laamanen CA, Shang H, Ross G, Scott JA (2017) Smelter off-gas waste heat and carbon dioxide sequestration to promote production of biodiesel. CIM J 8:1-12.

https://doi.org/10.15834/cimj.2017.11

9. Cheng J, Zhu Y, Zhang Z, Yang W (2019) Modification and improvement of microalgae strains for strengthening $\mathrm{CO} 2$ fixation from coal-fired flue gas in power plants. Bioresour Technol. https://doi.org/10.1016/j.biortech.2019.121850

10. Aslam A, Thomas-Hall SR, Mughal T, et al (2019) Heavy metal bioremediation of coal-fired flue gas using microalgae under different CO2 concentrations. J Environ Manag 241:243-250. https://doi.org/10.1016/j.jenvman.2019.03.118 
11. Ekendahl S, Bark M, Engelbrektsson J, et al (2018) Energy-efficient outdoor cultivation of oleaginous microalgae at northern latitudes using waste heat and flue gas from a pulp and paper mill. Algal Res 31:138-146. https://doi.org/10.1016/j.algal.2017.11.007

12. Gentili FG (2014) Microalgal biomass and lipid production in mixed municipal, dairy, pulp and paper wastewater together with added flue gases. Bioresour Technol 169:27-32. https://doi.org/10.1016/j.biortech.2014.06.061

13. Hsieh C-J, Zhan SH, Liao C-P, et al (2018) The effects of contemporary selection and dispersal limitation on the community assembly of acidophilic microalgae. J Phycol 54:720-733. https://doi.org/10.1111/jpy.12771

14. Hirooka S, Tomita R, Fujiwara T, et al (2020) Efficient open cultivation of cyanidialean red algae in acidified seawater. Sci Rep. https://doi.org/10.1038/s41598-020-70398-z

15. Ruiz-Domínguez MC, Vaquero I, Obregón V, et al (2015) Lipid accumulation and antioxidant activity in the eukaryotic acidophilic microalga Coccomyxa sp. (strain onubensis) under nutrient starvation. $J$ Appl Phycol 27:1099-1108. https://doi.org/10.1007/s10811-014-0403-6

16. Tan KM, Kassim MA, Ng ZJ, Lalung J (2020) Isolation and characterization of novel acidophilic microalgae from abandoned mining site area for carbohydrate biosynthesis and its kinetic growth study in photobioreactor. IOP Conf Ser: Mater Sci Eng. https://doi.org/10.1088/1757899x/716/1/012011

17. Srinuanpan S, Cheirsilp B, Prasertsan P, et al (2018) Strategies to increase the potential use of oleaginous microalgae as biodiesel feedstocks: Nutrient starvations and cost-effective harvesting process. Renewable Energy 122:507-516. https://doi.org/10.1016/j.renene.2018.01.121

18. Solovchenko A, Solovchenko O, Khozin-Goldberg I, et al (2013) Probing the effects of high-light stress on pigment and lipid metabolism in nitrogen-starving microalgae by measuring chlorophyll fluorescence transients: Studies with a $\Delta 5$ desaturase mutant of Parietochloris incisa (Chlorophyta, Trebouxiophyceae). Algal Res 2:175-182. https://doi.org/10.1016/j.algal.2013.01.010

19. Pancha I, Chokshi K, Maurya R, et al (2015) Salinity induced oxidative stress enhanced biofuel production potential of microalgae Scenedesmus sp. CCNM 1077. Bioresour Technol 189:341-348. https://doi.org/10.1016/j.biortech.2015.04.017

20. Sui Y, Jiang Y, Moretti M, Vlaeminck SE (2020) Harvesting time and biomass composition affect the economics of microalgae production. J Cleaner Prod. https://doi.org/10.1016/j.jclepro.2020.120782

21. Ananthi V, Brindhadevi K, Pugazhendhi A, Arun A (2021) Impact of abiotic factors on biodiesel production by microalgae. Fuel. https://doi.org/10.1016/j.fuel.2020.118962

22. Sharma AK, Sahoo PK, Singhal S, Joshi G (2016) Exploration of upstream and downstream process for microwave assisted sustainable biodiesel production from microalgae Chlorella vulgaris. Bioresour Technol 216:793-800. https://doi.org/10.1016/j.biortech.2016.06.013

23. Laamanen CA, Scott JA (2017) Development of heat-aided flocculation for flotation harvesting of microalgae. Biomass Bioenergy 107:150-154. https://doi.org/10.1016/j.biombioe.2017.09.020 
24. Lu Z, Loftus S, Sha J, et al (2020) Water reuse for sustainable microalgae cultivation: current knowledge and future directions. Resour Conserv Recycl.

https://doi.org/10.1016/j.resconrec.2020.104975

25. Jung J-H, Sirisuk P, Ra CH, et al (2019) Effects of green LED light and three stresses on biomass and lipid accumulation with two-phase culture of microalgae. Process Biochem 77:93-99. https://doi.org/10.1016/j.procbio.2018.11.014

26. lasimone F, Panico A, De Felice V, et al (2018) Effect of light intensity and nutrients supply on microalgae cultivated in urban wastewater: Biomass production, lipids accumulation and settleability characteristics. J Environ Manag 223:1078-1085. https://doi.org/10.1016/j.jenvman.2018.07.024

27. Seyed Hosseini N, Shang H, Scott JA (2018) Increasing microalgal lipid productivity for conversion into biodiesel by using a non-energy consuming light guide. Biochem Eng J 134:60-68. https://doi.org/10.1016/j.bej.2018.03.006

28. Bai X, Song H, Lavoie M, et al (2016) Proteomic analyses bring new insights into the effect of a dark stress on lipid biosynthesis in Phaeodactylum tricornutum. Sci Rep 6:25494. https://doi.org/10.1038/srep25494

29. Rizwan M, Mujtaba G, Memon SA, Lee K (2020) Influence of salinity and nitrogen in dark on Dunaliella tertiolecta's lipid and carbohydrate productivity. Biofuels. https://doi.org/10.1080/17597269.2020.1762275

30. Barros JAS, Magen S, Lapidot-Cohen T, et al (2021) Autophagy is required for lipid homeostasis during dark-induced senescence. Plant Physiol 185:1542-1558. https://doi.org/10.1093/plphys/kiaa120

31. Pugkaew W, Meetam M, Ponpuak M, et al (2018) Role of autophagy in triacylglycerol biosynthesis in Chlamydomonas reinhardtii revealed by chemical inducer and inhibitors. J Appl Phycol 30:15-22. https://doi.org/10.1007/s10811-017-1166-7

32. Couso I, Pérez-Pérez ME, Martínez-Force E, et al (2018) Autophagic flux is required for the synthesis of triacylglycerols and ribosomal protein turnover in Chlamydomonas. J Exp Bot 69:1355-1367. https://doi.org/10.1093/jxb/erx372

33. Bradley IM, Pinto AJ, Guest JS (2016) Design and Evaluation of Illumina MiSeq-Compatible, $18 \mathrm{~S}$ rRNA Gene-Specific Primers for Improved Characterization of Mixed Phototrophic Communities. Appl Environ Microbiol 82:5878-5891. https://doi.org/10.1128/AEM.01630-16

34. Andersen RA (2005) Algal culturing techniques, 1st ed. Elsevier Inc

35. Bligh EG, Dyer WJ (1959) A rapid method of total lipid extraction and purification. Can J Biochem Physiol 37:911-917. https://doi.org/10.1139/059-099

36. Morrison WR, Smith LM (1964) Preparation of fatty acid methyl esters and dimethylacetals from lipids with boron fluoride-methanol. J Lipid Res 5:600-608. https://doi.org/10.1016/S00222275(20)40190-7 
37. R Core Team (2018) R: A Language and Environment for Statistical Computing. R Foundation for Statistical Computing, Vienna, Austria

38. Wickham H (2016) ggplot2: Elegant Graphics for Data Analysis. Springer-Verlag New York

39. Vaquero I, Ruiz-Domínguez MC, Márquez M, Vílchez C (2012) Cu-mediated biomass productivity enhancement and lutein enrichment of the novel microalga Coccomyxa onubensis. Process Biochem 47:694-700. https://doi.org/10.1016/j.procbio.2012.01.016

40. Fuentes J-L, Montero Z, Cuaresma M, et al (2020) Outdoor Large-Scale Cultivation of the Acidophilic Microalga Coccomyxa onubensis in a Vertical Close Photobioreactor for Lutein Production. Processes 8:324. https://doi.org/10.3390/pr8030324

41. Vaquero I, Vázquez M, Ruiz-Domínguez MC, Vílchez C (2014) Enhanced production of a lutein-rich acidic environment microalga. J Appl Microbiol 116:839-850. https://doi.org/10.1111/jam.12428

42. Casal C, Cuaresma M, Vega JM, Vilchez C (2011) Enhanced productivity of a lutein-enriched novel acidophile microalga grown on urea. Mar Drugs 9:29-42. https://doi.org/10.3390/md9010029

43. Xie Y, Lu K, Zhao X, et al (2019) Manipulating Nutritional Conditions and Salinity-Gradient Stress for Enhanced Lutein Production in Marine Microalga Chlamydomonas sp. Biotechnol J. https://doi.org/10.1002/biot.201800380

44. Olaueson MM, Stokes PM (1989) Responses of the acidophilic alga euglena mutabilis (euglenophycae) to carbon enrichment at pH 3. J Phycol 25:529-539. https://doi.org/10.1111/j.1529-8817.1989.tb00259.x

45. Souza L dos S, Simioni C, Bouzon ZL, et al (2017) Morphological and ultrastructural characterization of the acidophilic and lipid-producer strain Chlamydomonas acidophila LAFIC-004 (Chlorophyta) under different culture conditions. Protoplasma 254:1385-1398. https://doi.org/10.1007/s00709016-1030-7

46. Rego D, Redondo LM, Geraldes V, et al (2015) Control of predators in industrial scale microalgae cultures with Pulsed Electric Fields. Bioelectrochem 103:60-64. https://doi.org/10.1016/j.bioelechem.2014.08.004

47. Fulbright SP, Robbins-Pianka A, Berg-Lyons D, et al (2018) Bacterial community changes in an industrial algae production system. Algal Res 31:147-156. https://doi.org/10.1016/j.algal.2017.09.010

48. Neves F de F, Hoinaski L, Rörig LR, et al (2019) Carbon biofixation and lipid composition of an acidophilic microalga cultivated on treated wastewater supplied with different $\mathrm{CO} 2$ levels. Environ Technol 40:3308-3317. https://doi.org/10.1080/09593330.2018.1471103

49. Deamici KM, Santos LO, Costa JAV (2018) Use of static magnetic fields to increase CO2 biofixation by the microalga Chlorella fusca. Bioresour Technol 276:103-109. https://doi.org/10.1016/j.biortech.2018.12.080

50. Sajjadi B, Chen W-Y, Raman AbdulAzizA, Ibrahim S (2018) Microalgae lipid and biomass for biofuel production: A comprehensive review on lipid enhancement strategies and their effects on fatty acid 
composition. Renewable Sustainable Energy Rev 97:200-232.

https://doi.org/10.1016/j.rser.2018.07.050

51. Venn-Watson S, Lumpkin R, Dennis EA (2020) Efficacy of dietary odd-chain saturated fatty acid pentadecanoic acid parallels broad associated health benefits in humans: could it be essential? Sci Rep. https://doi.org/10.1038/s41598-020-64960-y

52. Spijkerman E, Wacker A (2011) Interactions between P-limitation and different $C$ conditions on the fatty acid composition of an extremophile microalga. Extremophiles 15:597-609. https://doi.org/10.1007/s00792-011-0390-3

53. Maltsev Y, Maltseva I, Maltseva S, et al (2019) Fatty Acid Content and Profile of the Novel Strain of Coccomyxa elongata (Trebouxiophyceae, Chlorophyta) Cultivated at Reduced Nitrogen and Phosphorus Concentrations. J Phycol 55:1154-1165. https://doi.org/10.1111/jpy.12903

54. Caporgno MP, Mathys A (2018) Trends in microalgae incorporation into innovative food products with potential health benefits. Front Nutr. https://doi.org/10.3389/fnut.2018.00058

55. Krishna Koyande A, Chew KW, Rambabu K, et al (2019) Microalgae: A potential alternative to health supplementation for humans. Food Sci Hum Wellness 8:16-24. https://doi.org/10.1016/j.fshw.2019.03.001

56. Belury MA, Cole RM, Snoke DB, et al (2018) Linoleic acid, glycemic control and Type 2 diabetes. Prostaglandins, Leukotrienes and Essential Fatty Acids 132:30-33. https://doi.org/10.1016/j.plefa.2018.03.001

57. Marangoni F, Agostoni C, Borghi C, et al (2020) Dietary linoleic acid and human health: Focus on cardiovascular and cardiometabolic effects. Atherosclerosis 292:90-98. https://doi.org/10.1016/j.atherosclerosis.2019.11.018

58. Lacour T, Larivière J, Babin M (2017) Growth, Chl a content, photosynthesis, and elemental composition in polar and temperate microalgae. Limnology and Oceanography 62:43-58. https://doi.org/10.1002/Ino.10369

59. Huang Y, Luo L, Xu K, Wang XC (2019) Characteristics of external carbon uptake by microalgae growth and associated effects on algal biomass composition. Bioresour Technol 292:121887. https://doi.org/10.1016/j.biortech.2019.121887

60. Chu Q, Lyu T, Xue L, et al (2020) Hydrothermal carbonization of microalgae for phosphorus recycling from wastewater to crop-soil systems as slow-release fertilizers. J Cleaner Prod. https://doi.org/10.1016/j.jclepro.2020.124627

61. Arun J, Gopinath KP, Vigneshwar SS, Swetha A (2020) Sustainable and eco-friendly approach for phosphorus recovery from wastewater by hydrothermally carbonized microalgae: Study on spent biochar as fertilizer. J Water Process Eng. https://doi.org/10.1016/j.jwpe.2020.101567

62. Deepika P, MubarakAli D (2020) Production and assessment of microalgal liquid fertilizer for the enhanced growth of four crop plants. Biocatal Agric Biotechnol. https://doi.org/10.1016/j.bcab.2020.101701 
63. Santos FM, Pires JCM (2018) Nutrient recovery from wastewaters by microalgae and its potential application as bio-char. Bioresour Technol 267:725-731. https://doi.org/10.1016/j.biortech.2018.07.119

64. Nayak M, Swain DK, Sen R (2019) Strategic valorization of de-oiled microalgal biomass waste as biofertilizer for sustainable and improved agriculture of rice (Oryza sativa L.) crop. Sci Total Environ 682:475-484. https://doi.org/10.1016/j.scitotenv.2019.05.123

65. Taghipour A, Hornung U, Ramirez JA, et al (2021) Fractional distillation of algae based hydrothermal liquefaction biocrude for co-processing: changes in the properties, storage stability, and miscibility with diesel. Energy Convers Manage. https://doi.org/10.1016/j.enconman.2021.114005

66. Huang Y, Xu S, Lin VS-Y (2011) Bifunctionalized Mesoporous Materials with Site-Separated Brønsted Acids and Bases: Catalyst for a Two-Step Reaction Sequence. Angewandte Chemie International Edition 50:661-664. https://doi.org/10.1002/anie.201004572

67. Lu J, Wu J, Zhang L, et al (2020) Catalytic hydrothermal liquefaction of microalgae over mesoporous silica-based materials with site-separated acids and bases. Fuel. https://doi.org/10.1016/j.fuel.2020.118529

68. Wang K, Brown RC, Homsy S, et al (2013) Fast pyrolysis of microalgae remnants in a fluidized bed reactor for bio-oil and biochar production. Bioresour Technol 127:494-499. https://doi.org/10.1016/j.biortech.2012.08.016

69. Gong Z, Wang Z, Wang Z, et al (2019) Study on the migration characteristics of nitrogen and sulfur during co-combustion of oil sludge char and microalgae residue. Fuel 238:1-9. https://doi.org/10.1016/j.fuel.2018.10.087

\section{Figures}




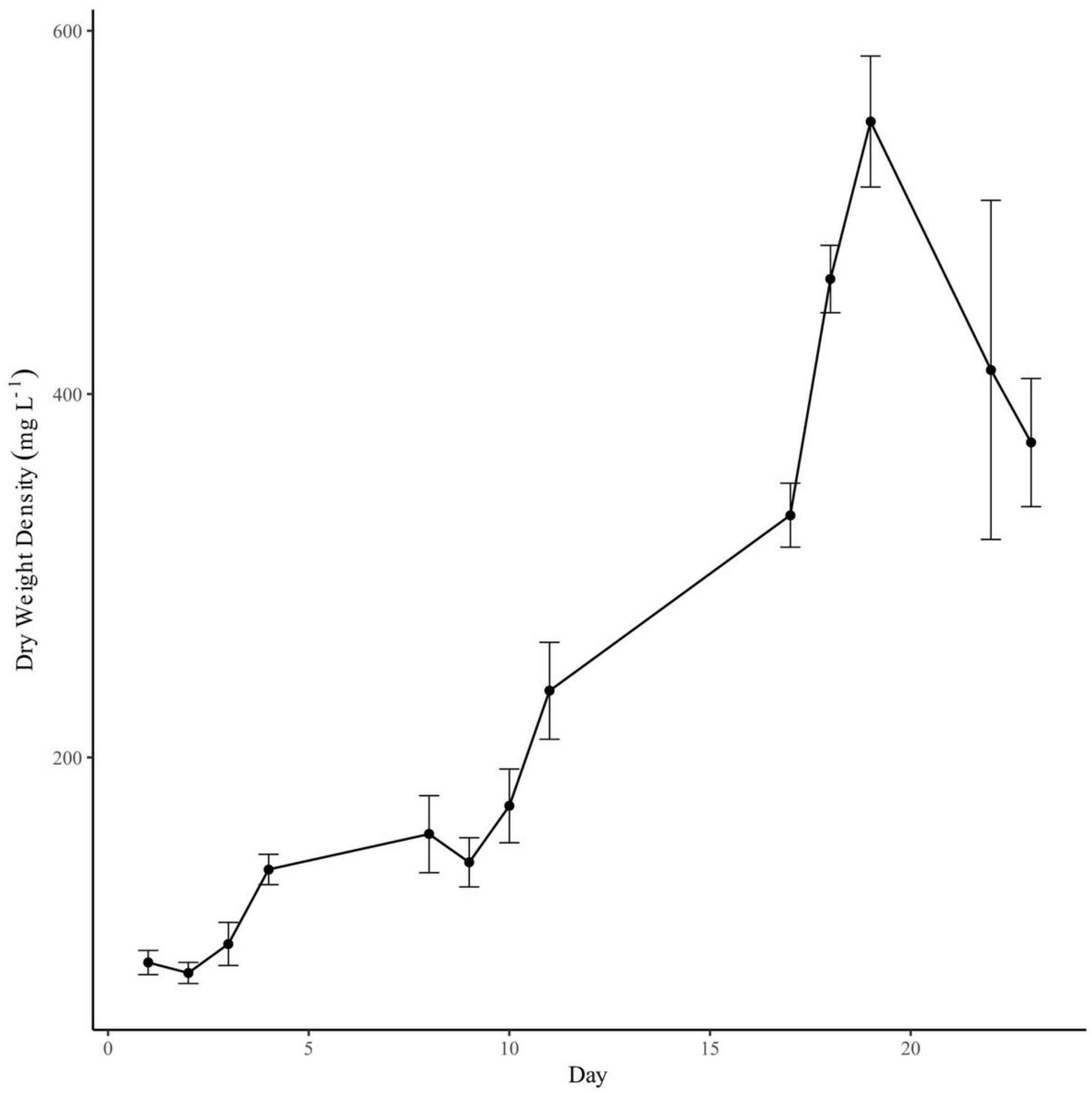

\section{Figure 1}

Growth curve (mean \pm standard error) of the Coccomyxa sp. consortium exposed to a 12-hour light/dark cycle and $6 \% \mathrm{CO} 2$ 


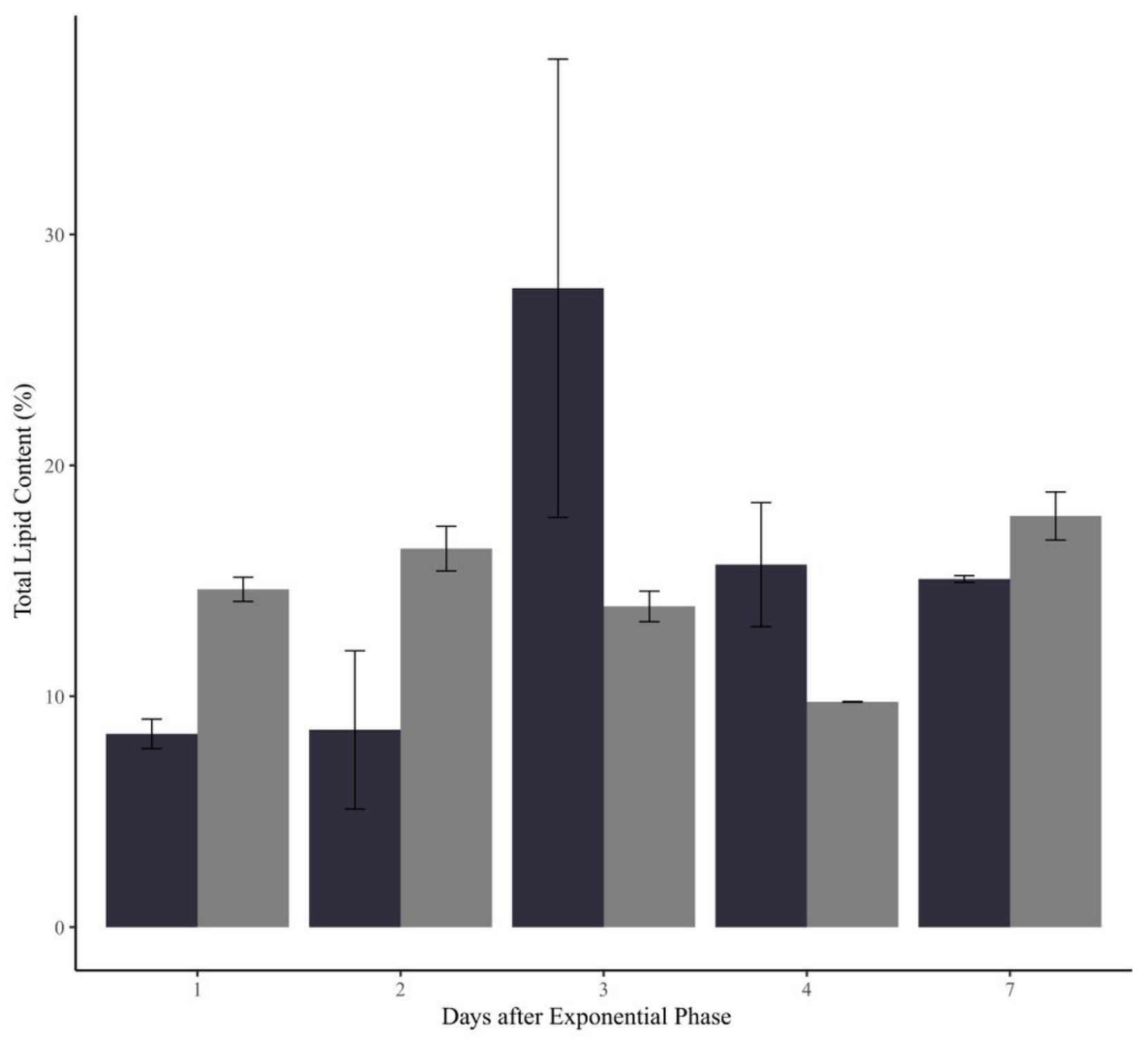

Experimental Measures

Dark Light

\section{Figure 2}

Total lipid content $(\%$, mean \pm standard error) of the dried biomass after the exponential phase 


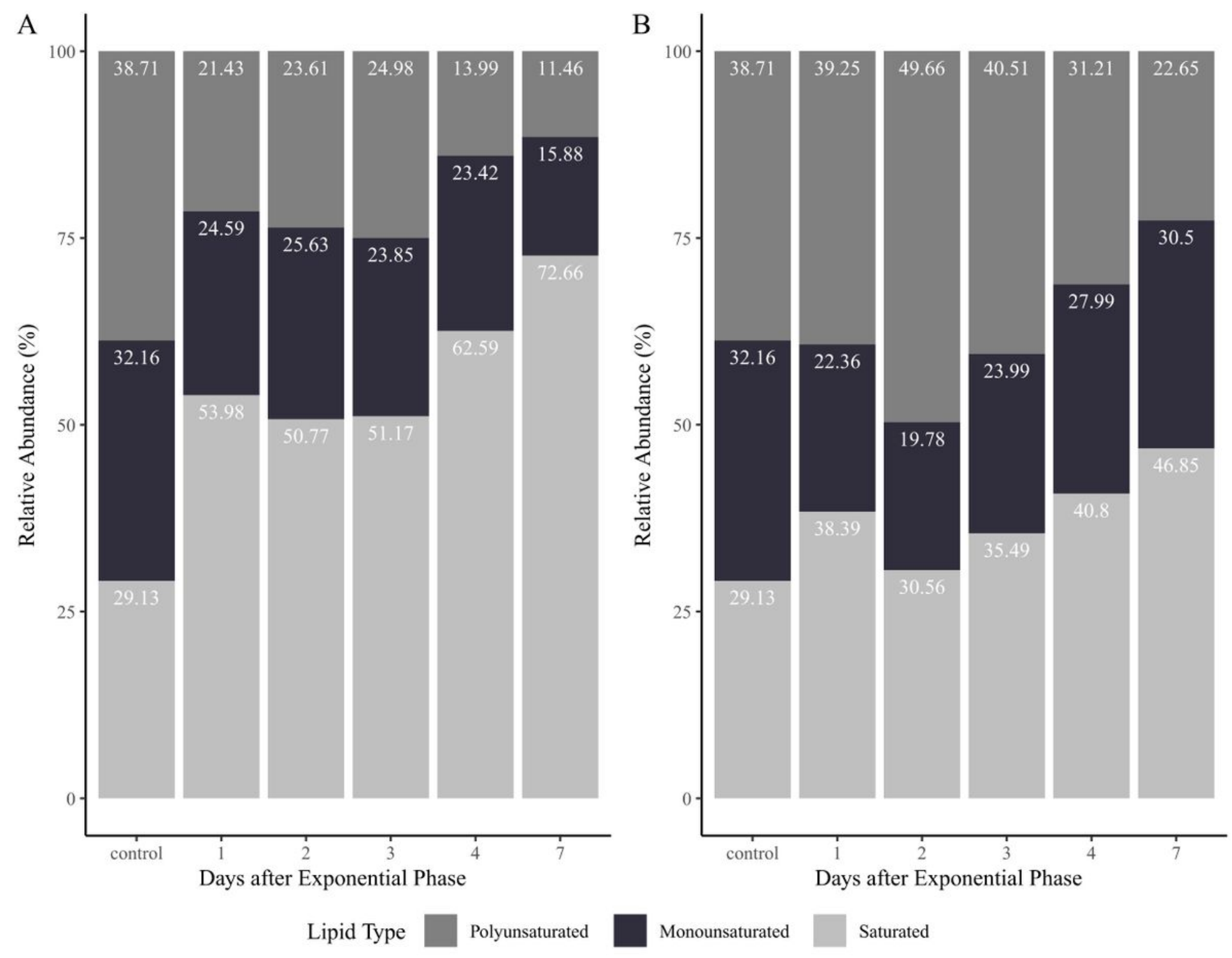

Figure 3

Lipid profile of Coccomyxa sp. consortium during A) light-dark growing conditions (12-hour light/dark cycle, $6 \% \mathrm{CO} 2$ ) and $\mathrm{B}$ ) under continual dark conditions. The control is the lipid profile at the end of the exponential phase 